\title{
Desafios do planejamento em políticas públicas: diferentes visões e práticas*
}

\author{
José Antônio Puppim de Oliveira**
}

S UMÁRIO: 1. Introdução; 2. Visões típicas de planejamento e implementação de políticas públicas; 3. A literatura de planejamento e implementação de políticas públicas; 4. O que é planejamento? 5. Considerações finais.

SUMmary: 1. Introduction; 2. Typical views of public policy planning and implementation; 3. Literature on public policy planning and implementation; 4. What is planning? 5. Final remarks.

P A L A VR A S-CH A VE: planejamento; políticas públicas; implementação; Brasil.

KEY WORD S: planning; public policies; implementation; Brazil.

Este artigo analisa conceitualmente as diversas maneiras de se pensar planejamento, particularmente com respeito a políticas públicas. O artigo focaliza principalmente os problemas de planejamento nos chamados países em desenvolvimento, em especial no Brasil. Esses problemas estão relacionados à ênfase dada ao tecnicismo, à burocracia de formulação e controle e às previsões dos economistas. Isso tende a colocar sombra na parte mais importante do planejamento: o processo de decisão, que é uma construção política e social. O artigo mostra que o planejamento em políticas públicas tem de ser visto como um processo, e não como um produto técnico somente. A importância do processo se dá principalmente na implementação, pois esta é que vai levar aos resultados finais das políticas, programas ou projetos. O artigo argumenta que o planejamento é um processo de decisão político-social que depende de informações precisas, transparência, ética, temperança, aceitação de visões diferentes e vontade de negociar e buscar soluções conjuntas que sejam aceitáveis para toda a sociedade, principalmente para as partes envolvidas, levando continuamente ao aprendizado.

\footnotetext{
* Artigo recebido em ago. e aceito em dez. 2005. Versões deste artigo foram publicadas nos anais do Enanpad 2005 e em Martins e Pieranti (2006).

** Professor adjunto da Ebape/FGV. Endereço: Praia de Botafogo, 190, sala 507 — Botafogo — CEP: 22250-900, Rio de Janeiro, RJ, Brasil. E-mail: puppim@fgv.br.
} 


\section{Challenges of public policy planning: different views and practices}

This article analyzes the different ways policymakers and academia deal with public policy planning especially in developing countries, Brazil in particular. It points out that many public policy problems in developing countries are related to the way planning is carried out, as a technicist and bureaucratic activity, centralized in the hands of economists and focused on prediction models. This leads to shortcomings in the main points of the planning activity: the decision-making process, which is a social and political construction. After reviewing the history of planning in Brazil and in the world, the text argues that planning in Brazil needs less simulations and econometric models, and more precise information, transparency, ethics and common sense to accept different views, as well as a willingness to negotiate and involve the stakeholders.

\section{Introdução}

Muitas pessoas vêem planejamento como uma questão de fazer planos, delegar responsabilidades, se necessário passar leis e determinar o orçamento. No Brasil, especialmente em nível federal, o planejamento ainda é visto como uma coisa quase que estritamente tecnicista dominada por economistas e burocratas. Eles assumem que uma vez tendo o plano certo, a implementação sairá automaticamente. Porém, a realidade tem sido diferente: muitos projetos, programas e políticas falham na implementação como planejado ou têm impactos negativos inesperados. Temos longas décadas de experiências fracassadas de planejamento, com planos mirabolantes ou megalômanos, que no papel funcionam, mas não na prática, onde alcançam resultados decepcionantes ou desastrosos. Exemplos incluem a Transamazônica, o Polonoroeste e atualmente o famigerado Fome Zero, sem falar nos incontáveis e catastróficos planos econômicos. Somas consideráveis de recursos são gastas, e só contribuem para o alongamento das décadas perdidas. Por que costumamos falhar então?

Este artigo tenta responder essa pergunta. Ele faz uma análise conceitual sobre as diversas maneiras de se pensar planejamento, particularmente com respeito a políticas públicas. Focaremos principalmente nos problemas de planejamento nos chamados países em desenvolvimento, em especial no Brasil. A ênfase dada à burocracia de formulação e controle e às previsões dos economistas tende a colocar sombra na parte mais importante: o processo de decisão, que é uma construção política e social. Mostraremos que o planejamento em políticas públicas tem que ser visto como um processo, e não como um produto técnico somente. A importância do processo se dá principalmente na implementação, pois esta é que vai levar aos resultados finais das políticas, programas ou projetos.

O artigo segue primeiramente com uma análise de algumas visões típicas de planejamento que se encontram na prática. A seguir, examina a relação entre plane- 
jamento e implementação de políticas públicas, com ênfase nos países em desenvolvimento. Finalmente, colocaremos a evolução do conceito de planejamento, contrastando com o que se pensa sobre planejamento no Brasil.

2. Visões típicas de planejamento e implementação de políticas públicas

Um dos motivos que leva a falhas nos resultados de políticas públicas é a dissociação que se faz entre elaboração e implementação no processo de planejamento de acordo com algumas visões da prática ou escolas de pensamento.

Uma primeira escola vê o processo de planejamento de políticas públicas associado a atividades de elaborar-se planos, com isso envolvendo tomada de decisões políticas, reuniões de discussão, mapas detalhados, modelos matemáticos e cenários, criação de legislação e distribuição de responsabilidades, e ao final se gera um plano. Uma vez que terminem essas etapas, assume-se que automaticamente as ações planejadas serão implementadas e atingirão os resultados esperados, se o plano foi bem-feito e tiver o orçamento aprovado. Assim a avaliação de um processo de planejamento é vista primordialmente sobre a ótica de confeccionar planos. Caso o plano desenhado inicialmente seja bom, o resultado ao final será bom. Se o plano é ruim, o resultado é ruim. O que necessitam as políticas públicas é de bons "planejadores" com mentes privilegiadas e "visão de futuro" para se anteceder ao que vem no futuro e fazer planos corretos que levem aos resultados calculados. Os projetos de irrigação na região de Juazeiro (BA) e Petrolina (PE) são citados como um exemplo de plano bem-sucedido com o caráter descrito acima.

Uma outra visão de planejamento reconhece o papel da implementação, mas ainda enfatiza a elaboração de planos como chave primordial para o sucesso de políticas públicas. Nela, como na visão anterior, existem bons e maus planos. Porém, segundo essa visão, muitos dos bons planos falham porque houve problemas técnicos na implementação, foram sabotados ou não foram implementados exatamente de acordo com o que foi indicado no plano. Exemplos deste tipo de visão de planejamento incluem alguns planos elaborados na época da ditadura militar no Brasil, como a colonização da Amazônia com a construção de estradas (Transamazônica) e assentamentos (Polonoroeste).

Uma versão um pouco mais moderna desta visão de planejamento tenta adicionar uma componente de implementação no plano. Com isso priorizam-se alguns mecanismos de gestão da implementação dos planos para garantir que aquilo indicado no plano vai ser implementado. Esses mecanismos incluem monitoramento, auditorias e reuniões técnicas de acompanhamento. Porém, por mais que se fiscalize, os resultados muitas vezes ainda são insatisfatórios porque houve diversos tipos de problemas institucionais, muito do planejado não era executável ou as condições ini- 
ciais mudaram com o tempo. Temos como exemplo o Projeto de Despoluição da Baía de Guanabara (PDBG) no Rio de Janeiro, onde foram gastos centenas de milhões de dólares sem conseguir os resultados esperados, apesar de todas as precauções tomadas no acompanhamento técnico da implementação do projeto.

Ainda temos a visão popular ou populista, ou “politicamente correta” nos dias de hoje, do planejamento com total ênfase na participação da população ou sociedade civil na implementação dos planos. Essa visão está em moda nos últimos anos, principalmente com as organizações multilaterais e alguns setores do governo. Aqui os beneficiários têm que ajudar a monitorar o projeto, denunciar, participar de assembléias etc. Muitas vezes criam-se “conselhos populares” para decidir e acompanhar ou chamam a sociedade e empresas para ajudar. Um exemplo é o famigerado programa Fome Zero do governo federal, que peca pela sua lentidão e falta de resultados.

Essas visões descritas anteriormente separam claramente a elaboração da implementação de políticas públicas no processo de planejamento, e colocam o planejamento como um processo de fazer-se planos. Temos visto os resultados decepcionantes, e às vezes catastróficos, da concepção equivocada do processo de planejamento que alija a elaboração da implementação de políticas públicas, temos vários exemplos na prática, como as políticas para o desenvolvimento da Amazônia no Brasil na década de 1970 (Moran, 1983; Lutzenberger, 1985). Porém parece que não aprendemos a lição ainda. Temos hoje a determinação do governo federal com planos mirabolantes, como por exemplo a idéia de fazer a transposição do rio São Francisco.

\section{A literatura de planejamento e implementação de políticas públicas}

\section{Implementação de políticas públicas e planejamento}

A literatura de políticas públicas foi um pouco tardia em reconhecer a importância da implementação no processo de planejamento, até mesmo porque os estudiosos de políticas públicas tinham um viés tradicional das ciências políticas, tendo um foco de análise nos processos legislativos ou administrativos do Executivo (Najam, 1995). Assim, o importante a ser pesquisado seria entender como os assuntos chegam à agenda política, quais são os processos legislativos de aprovação de leis, como eleições são ganhas ou perdidas, como órgãos burocráticos são criados, como são indicados os responsáveis por determinados cargos etc. Ainda hoje, no Brasil, existe muito esta visão em relação ao que é importante para definir políticas públicas na prática. 
Um dos primeiros trabalhos a alertar para a importância de entender a implementação em políticas públicas foi o trabalho de Pressman e Wildavsky (1973). O livro analisava um programa de desenvolvimento econômico de apoio a minorias étnicas estabelecido por uma agência que havia sido recentemente criada nos Estados Unidos em nível federal, a Economic Development Administration (EDA). Os planos elaborados pela EDA em Washington chegaram com grande expectativa de resultados, mas falharam espetacularmente na sua implementação. Os autores ficaram impressionados com a falta de atenção da literatura acadêmica para a questão da implementação de políticas públicas. Esse trabalho foi uma referência na literatura americana e internacional de políticas públicas da época.

O alerta de Pressman e Wildavsky parece que teve algum efeito na produção intelectual na área. Nos anos que se seguiram à publicação de Implementação, vários trabalhos foram elaborados (Rein e Rabinovitz, 1977; Bardach, 1977; Berman, 1978; Elmore, 1979). A literatura continuou abordando o tema nas décadas seguintes (Mazmanian e Sabatier, 1983; Najam, 1995; Grindle, 1988). Porém, já se passaram mais de 30 anos desde a publicação do trabalho de Pressman e Wildavsky e permanecem vários debates sobre implementação nos campos de conhecimento relacionados a políticas públicas, tais como planejamento, administração, ciências políticas e economia aplicada. Os debates vão desde técnicas para estudar e administrar implementação, até a diferença entre implementação nos países desenvolvidos e em desenvolvimento.

Mesmo chegar a um consenso sobre a definição de implementação não é fácil, ou possível. Existe um emaranhado de definições e interpretações de implementação. A seguir, dois exemplos.

Implementação trata-se de como políticas mudam à medida que elas passam de diretivas administrativas para prática com (1) uma declaração governamental de suas preferências, (2) mediada por um número de atores sociais que (3) criam um processo circular caracterizado por relações recíprocas de poder e negociação.

(Rein e Rabinovitz, 1977)

Implementação é os eventos e atividades que ocorrem depois da emissão de autorizações e de diretrizes de políticas públicas, que incluem os esforços para administrá-las e gestionar seus impactos em pessoas e eventos.

(Mazmanian e Sabatier, 1983)

Na realidade, o estudo de implementação requer um entendimento de sua complexidade e de sua interação com o processo de planejamento. O resultado de um processo de planejamento, incluindo sua implementação, tem que ser visto como 
uma série de eventos aparentemente simples, mas que dependem de uma cadeia complexa de interações recíprocas para que obtenham o resultado esperado, e muitas vezes esta cadeia não pode ser prevista ou controlada.

A literatura de implementação pode ser dividida em gerações segundo alguns autores (Goggin et al., 1990; Najam, 1995). Logo após a publicação de Implementação houve uma primeira geração de estudos destacando a falta de debate sobre implementação, e criou-se uma agenda de pesquisa para seu melhor entendimento, de maneira a direcionar o campo das políticas públicas na teoria e prática. Embora essa primeira geração tenha sido importante para colocar a questão da implementação na agenda de pesquisa sobre políticas públicas, os estudos foram apontados como muito específicos em determinados casos, tinham uma visão pessimista e não tinham um embasamento teórico adequado nem se preocupavam com a construção de conhecimento na área (Goggin et al., 1990).

Uma segunda geração da literatura de implementação tentou construir teorias usando um número maior de casos em suas pesquisas, com o objetivo de criar uma análise através da construção de modelos para determinar variáveis relevantes e explicar as relações de causalidade no processo de implementação (Mazmanian e Sabatier, 1983; Van Meter e Van Horn, 1975). Porém, o que aconteceu foi uma proliferação de modelos que não eram compatíveis entre si ou generalizáveis e que não podiam ser replicados em outros contextos ou casos. Essa literatura ajudou a identificar as variáveis que poderiam ser importantes no processo de implementação, levando a uma terceira geração.

Essa terceira geração combinou trabalhos conceituais e empíricos, em vez de criar modelos. Os trabalhos aqui tentavam identificar as variáveis-chave para explicar por que a implementação tem bons resultados em alguns casos e não em outros (Goggin et al., 1990; Najam, 1995; Grindle, 1980).

Além dos debates acima sobre como se deveria pesquisar implementação para seu melhor entendimento, o desenvolvimento da literatura de implementação levou a uma série de discussões no âmbito das políticas públicas. Uma das mais interessantes discussões, que ainda continua nos dias de hoje, trata-se da maneira como o processo de planejamento deve ser visto em relação à direção no fluxo das decisões. Um grupo acredita que o processo pode ser controlado de cima para baixo (top down), ou seja, as decisões são tomadas por autoridades que têm um certo controle do processo e decidem o que e como serão implementadas as políticas (Mazmanian e Sabatier, 1983; Van Meter e Van Horn, 1975). Com isso, elas poderiam efetivamente coordenar o processo de planejamento de políticas públicas.

Uma visão rival, e de certa forma antagônica, enfatiza a importância de se levar em consideração no fluxo do processo de planejamento aqueles que estão mais próximos às ações resultantes das políticas, ou seja, vêem o processo de baixo para cima (bottom up) (Elmore, 1979; Lipsky, 1980; Kaufman, 1973). Dessa forma, a 
população afetada pela política e os agentes do Estado em contato com ela (chamados street-level bureaucrats, ou burocratas da rua) poderiam e deveriam influenciar de forma mais intensa o processo de planejamento de políticas públicas. De acordo com autores que apóiam essa visão, ela seria justificada, primeiramente, por questões de efetividade e eficiência, já que esses atores sabem exatamente o que acontece e o que seria melhor para alcançar-se os resultados da política (Palumbo e Harder, 1981); segundo, porque seria mais democrático a participação das partes interessadas no processo nas decisões que lhes afetam. Na mesma época da emergência da escola do bottom up acontecia um crescimento da literatura sobre descentralização (Rondinelli, 1981), que justificava da mesma forma sua necessidade em políticas públicas. Os defensores do processo de cima para baixo (top down), entretanto, eram céticos em relação à ênfase dada às necessidades de ter um fluxo mais intenso de baixo para cima, pois os atores mais abaixo no processo muitas vezes não tinham uma visão do todo e sobre como controlar o processo. Ao final, houve uma certa convergência em aceitar a importância de ambos os fluxos (top down e bottom up) para se entender políticas públicas e seu processo de planejamento.

\section{A literatura de planejamento e implementação em países em desenvolvimento}

Um debate quase separado na literatura internacional é o estudo da implementação e do processo de planejamento nos países em desenvolvimento. Alguns autores não fazem distinção em seus modelos e estudos entre os países desenvolvidos e em vias de desenvolvimento (Van Meter e Van Horn, 1975), mas boa parte da literatura internacional faz essa divisão. Os debates nas duas divisões tomam rumos diferentes e influenciam uns aos outros (Grindle, 1980). A divisão desenvolvido/em desenvolvimento tem em suas raízes a premissa, que nunca foi testada, de que as condições e o processo de planejamento nos dois tipos de países são substancialmente diferentes. Assim a literatura nos países em desenvolvimento tem sido diferente em três aspectos (Najam, 1995).

t Ela é baseada em estudos de caso e utiliza menos os modelos devido à grande diversidade nos contextos social, cultural e político.

t Ela também tende a enfatizar as influências de cima para baixo no processo de planejamento. 
t Finalmente, a literatura internacional assume que os países em desenvolvimento têm maiores dificuldades técnicas, financeiras e culturais no processo de planejamento e implementação de políticas públicas.

Outro aspecto da implementação em países em desenvolvimento vem se desenvolvendo mais recentemente. Alguns estudos de políticas públicas têm-se centrado mais em entender o processo de planejamento como um só, sem tanta separação entre elaboração e implementação de políticas públicas com uma ênfase no estudo de casos particularmente exitosos e com destaque para os países em desenvolvimento (Oliveira, 2002; Grindle, 1988; Tendler, 1987).

Existem vários aspectos para tentar diferenciar o processo de planejamento de políticas públicas entre países desenvolvidos e em desenvolvimento. Há uma tendência a explicar as falhas de políticas públicas em países em desenvolvimento por vários motivos, entre os quais destacam-se os aspectos político-institucionais, financeiros e técnicos (Oliveira, 2002). A seguir, descreveremos alguns desses pontos que limitam o planejamento de políticas públicas.

Primeiro, estão os aspectos políticos e institucionais. O sistema político, Estado e sociedade civil nos países em desenvolvimento não estão articulados e nem funcionando de maneira apropriada. Muitos Estados em países em desenvolvimento foram criados recentemente (não inclui o Brasil no caso). Alguns saíram há poucas décadas do colonialismo, outros foram criados por divisões internas. Assim, em muitos desses países o Estado ainda está se formando. Outros tiveram longos períodos de ditaduras, o que inibiu a sociedade civil e o bom funcionamento do sistema político, e conseqüentemente a atuação do Estado. O economista Joel Migdal, um dos primeiros acadêmicos especializados em países em desenvolvimento, caracterizaria esses países como sociedades fortes em Estados fracos (Migdal, 1988). Isto dificultaria a articulação da sociedade e Estado.

Um segundo aspecto para explicar a diferença em países desenvolvidos e em desenvolvimento é a capacidade financeira. Esta geralmente é a razão mais direta para explicar as falhas em planejamento nos países em desenvolvimento. Os países em desenvolvimento têm menos recursos para serem aplicados nas diversas áreas, com isso a capacidade desses países de levar adiante políticas públicas de maneira que tenham resultados efetivos é limitada. Muitos desses países ou regiões dependem de doações ou empréstimos das agências multilaterais.

Terceiro, a capacidade técnica de gestionar o planejamento de políticas públicas é apontada como outro limitador dos países em desenvolvimento. Faltam recursos humanos capacitados e motivados, equipamentos, experiência e competência técnica dos órgãos responsáveis para planejar as políticas públicas. Muitas vezes existe uma centralização exagerada do processo de planejamento (Manor, 1999), falta uma articu- 
lação entre as diversas agências responsáveis para o bom andamento de determinadas políticas públicas ou até mesmo aparecem conflitos entre os órgãos no mesmo nível ou diferentes níveis de governo. Esses conflitos limitam o processo de planejamento.

Porém, alguns desses aspectos têm mudado nos últimos anos, particularmente no Brasil, mas muitas vezes sem conseguir melhores resultados na efetividade de políticas públicas. Temos visto uma democratização crescente dos países em desenvolvimento. Na América Latina isto fica claro, já que boa parte dos países da região saiu de regimes ditatoriais para regimes democráticos, apesar de ainda em formação. No Brasil, os quase 20 anos de democracia não parecem suficientes para o estabelecimento de um sistema político-institucional efetivo no planejamento. Existem diversos conflitos quanto à jurisdição e distribuição de responsabilidades entre os diferentes níveis de governo e organizações do Estado, além da pouca accountability (ou capacidade de resposta institucional, ver Campos, 1990) dessas organizações.

Quanto às questões financeiras, isto ainda continua limitando o planejamento de políticas públicas, mesmo com o aumento significativo da arrecadação, como no caso do Brasil. Boa parte dos países no mundo em desenvolvimento depende de recursos externos, ou tem uma porção significativa de seu orçamento dedicada a pagamento de dívidas públicas ou a cobrir déficits setoriais. O Brasil, apesar de a arrecadação do Estado chegar a quase $40 \%$ do produto interno bruto (PIB), dedica boa parte de seus recursos públicos para pagamento de dívida, folha salarial ou cobrir os rombos da previdência. Assim, mesmo com uma quantidade de recursos razoáveis o Estado não consegue direcionar uma quantidade significativa para investimento em políticas públicas, limitando a capacidade de planejamento.

Finalmente, temos a evolução dos aspectos da capacidade de gestão do planejamento de políticas públicas. Muitos países em desenvolvimento avançaram com respeito à capacitação técnica das organizações de Estado, mas ainda falta uma melhor articulação entre as várias organizações envolvidas no planejamento das diversas políticas públicas. Este talvez seja o aspecto mais limitador do planejamento nos países em desenvolvimento, em particular o Brasil. Os recursos humanos e equipamentos existem e muitas das organizações estatais estão capacitadas, mas o processo de planejamento de políticas públicas em geral exige a interação de diversas organizações dentro do Estado, e destas com a sociedade civil e setor privado. Nesses aspectos, ligados ao que seria o "capital social” do planejamento, ainda falta uma melhora em termos qualitativos. Ainda vemos muito o planejamento como um processo técnico, governamental, de caráter econômico e visionário.

4. O que é planejamento? 


\section{Planejamento no Brasil: uma visão de literatura clássica}

No Brasil, planejamento sempre esteve ligado à elaboração de planos e a controle. Historicamente, verificamos a quantidade de planos que já foram e continuam sendo elaborados: trienais, decenais, econômicos, plurianuais, de desenvolvimento, regionais, diretores etc. Temos uma cultura de planos, com a idéia de antever e organizar o futuro, como se isso fosse possível de maneira racional e previsível. A idéia de controle também está presente. Quando analisamos as funções das secretarias ou do Ministério de Planejamento percebemos um caráter altamente controlador. Suas atribuições principais sempre giram ao redor de controlar o orçamento e a alocação de recursos para diferentes órgãos estatais e projetos.

De modo interessante, nós, brasileiros, geralmente temos uma visão positiva do planejamento, diferente dos norte-americanos, muitos dos quais vêem com desconfiança o planejamento, por ser uma forma de intervenção do Estado nos indivíduos e organizações (idéia que vai contra os valores tradicionais americanos de liberdade individual e privacidade). Aqui nosso sentimento positivo possivelmente vem até mesmo porque nos sentimos desolados com os péssimos resultados dos nossos planos e vemos a necessidade de controlar e fazer planos "que dêem certo" para o futuro (quem sabe não virá um plano que vai dar certo?).

A própria literatura brasileira clássica na área de planejamento o vê de forma simplista (Lafer, 1970; Matus, 1993). O planejamento é visto como o processo de elaborar planos e tentar controlar o futuro, dividido em várias etapas seqüenciais (estabelecer objetivos, fazer planos, executá-los etc.), como se fosse uma receita de bolo controlar o futuro. Também existe um viés economicista, em que o planejamento é econômico e puramente governamental (Ianni, 1979; Lopes, 1990), como se os governos pudessem ter controle da economia. Assim, a cultura de planejamento do Brasil ainda vive um pouco da época do milagre econômico dos anos 1960 e 1970 e da utopia do "Estado desenvolvimentista", ligada ao conceito de planejamento da primeira metade do século passado. Vivemos a ilusão de simplificar a realidade complexa do que é o processo de planejamento. Porém, o que é planejamento?

\section{A evolução do que é planejamento}

A idéia de planejamento apareceu há aproximadamente um século com o objetivo de tentar controlar de alguma forma o futuro com documentos chamados planos. Primeiramente, de forma concreta, ela surgiu como planejamento espacial, no campo de planejamento de cidades no final do século XIX e início do século XX na Inglaterra. Criou-se o conceito de cidade jardim (Howard, 1902), onde se poderia planejar uma cidade para que fosse mais amena distribuindo espacialmente suas funções. Isto foi uma 
resposta ao caótico crescimento das cidades européias na época, resultando em poluição, congestionamento e má qualidade de vida. Este conceito teve um impacto grande na área de urbanismo do século passado, com o aparecimento de várias cidades-jardim ao redor do mundo (a concepção de Brasília teve influência de uma evolução desse conceito). Nesse ponto, planejamento era uma função estritamente técnica do urbanista ou arquiteto, que seria uma espécie de visionário. Esta aura de visionário no planejamento continua existindo um pouco até os dias de hoje.

Com a criação da União Soviética no final da década de 1910, uma outra vertente de planejamento apareceu: o planejamento econômico centralizado. Nele, o Estado teria completo controle sobre os recursos e os distribuiria de acordo com planos e metas determinados por políticos ou burocratas. Havia completa ausência de democracia na determinação do plano. Aqui identificamos o perfil controlador do planejamento, um pouco da idéia que ainda permanece no Brasil, onde o planejamento tem função controladora e é dominado por políticos e burocratas, além do caráter governamental e econômico.

A partir das décadas de 1930, 1940 e 1950, a vertente espacial-urbanística do planejamento nos EUA e Europa encampou uma forma mais abrangente englobando as esferas social e econômica do planejamento, talvez como resultado da influência da vertente soviética do planejamento, cujo regime político orientador se expandia pelos países do Leste europeu e Ásia. Nessa época, além do avanço das idéias keynesianas de forte intervenção estatal nas economias do mundo capitalista, começou a ganhar força também a vertente de planejamento e políticas de desenvolvimento regional, que culminou com a criação das agências em desenvolvimento, como Tennessee Valley Authority (TVA) nos EUA, Cassa per il Mezzogiorno na Itália, e Sudene e Sudam no Brasil. Nessa época ainda havia a idéia de planejamento como fazer planos para controlar o futuro, e um forte papel governamental nas decisões do planejamento.

Nesse ponto, o planejamento ainda era dividido em fases seqüenciais. Não era questionado o caráter seqüencial e compreensivo do planejamento. A partir dos anos 1950, começou uma discussão mais acalorada sobre a "compreensividade” e racionalidade controlada do planejamento, com a abordagem do mudling through (Lindblom, 1959; Branch Jr., 1959). Nessa abordagem o planejamento era um processo incremental (escola incrementalista do planejamento), de idas e voltas, e não uma seqüência linear de ações. Reconheciam-se as limitações do planejamento em ter informações para prever e via-se no planejamento um caráter de avançar pouco a pouco nas decisões e ações, e com isso lidar com situações muitas vezes inesperadas e imprevisíveis. Abnegava-se a idéia de que o planejamento poderia prever e controlar tudo, mas ele ainda era visto como um instrumento técnico. Mais ou menos na mesma época, no bojo do movimento de direitos civis dos EUA, surgiu a idéia de que o planejamento não deveria ser um instrumento estritamente técnico, e 
sim político. O planejamento deveria servir como instrumento de mudança social e de "advocacia", principalmente em favor dos interesses dos menos favorecidos social e politicamente, o chamado advocacy planning pelos proponentes do movimento (Davidoff, 1965).

As transformações no conceito de planejamento continuaram a partir da década de 1970 e em diante. O planejamento já não era mais tão visto como um instrumento técnico, e deveria ser um instrumento político, mas nem tanto de advocacy, e sim para moldar e articular os diversos interesses envolvidos no processo de intervenção de políticas públicas. O planejador deveria ser o mediador dos interesses da sociedade no processo, e o resultado final deveria ser tomado preferivelmente em consenso (Susskind e Kruikshank, 1987). Com o crescimento das organizações envolvidas no processo de planejamento e as interações entre elas, a chamada sociedade em rede (Castells, 1997), o planejamento passou a ser um processo acoplado à qualidade das interações entre os diversos atores envolvidos (Brinkerhoff, 1996; Hibbard e Lurie, 2000; Oliveira, 2005). Surgiu, então, o conceito de planejamento colaborativo, que buscava um processo de construção de confiança nas decisões do planejamento de políticas públicas (Healey, 1997). O planejamento assim se solidificou como um processo que depende da maneira como acontecem as relações de confiança entre as diversas partes interessadas e influenciadas pelas decisões. A idéia do aprendizado nas interações nos processos de decisão passou a ser cada vez mais relevante para pensar-se planejamento. Portanto, o processo de planejamento é um processo de decisão político que depende de informações precisas, transparência, ética, temperança, aceitação de visões diferentes e vontade de negociar e buscar soluções conjuntamente que sejam aceitáveis para toda a sociedade e principalmente para as partes envolvidas.

\section{Considerações finais}

A resposta à pergunta feita inicialmente, "Por que costumamos falhar?” no planejamento, está relacionada à ênfase que damos no Brasil ao planejamento como forma de se tentar o controle da economia e da sociedade, em vez de vê-lo como um processo de decisão construído política e socialmente com os diversos atores interessados e afetados pela decisão. Porém, por outro lado, essa construção tem que ser baseada em informações precisas e capacidade de articulação e compreensão do processo e dos temas debatidos pelos diversos atores envolvidos. Não podemos cair no participativismo populista e demagógico que vemos em algumas políticas públicas. Ao mesmo tempo, o processo de planejamento tem que ser visto como um processo que, com o tempo, leve à geração de confiança e aprendizado entre os diversos atores envolvidos na decisão para que se aprimorem na tomada de decisão conjunta.

Além disso, temos que reconhecer as limitações do planejamento como ferramenta capaz de prever e controlar o futuro, da idéia do "visionário" do líder iluminado. Temos que aceitar o papel do planejamento como construtor e articulador de 
relações na sociedade ou na organização que busca seu bem comum de maneira ética, justa e responsável. Infelizmente, não temos o poder de controlar e prever o futuro; nem nós nem ninguém.

\section{Referências bibliográficas}

BARDACH, Eugene. The implementation game: what happens after a bill becomes a law. Cambridge, MA: MIT Press, 1977.

BERMAN. Paul. The study of macro and micro-implementation. Public Policy, v. 26, n. 2, p. 157-184, 1978.

BRANCH JR., Melville C. Comprehensive planning: a new field study. Journal of the American Planning Association, v. 25, n. 3, p. 115-120, 1959.

BRINKERHOFF, Derick W. Coordination issues in policy implementation networks: an illustration from Madagascar's environmental action plan. World Development, v. 24, n. 9, p. 14971510, 1996.

CAMPOS, Anna Maria. Accountability: quando poderemos traduzi-la para o português. Revista de Administração Pública, Rio de Janeiro, v. 24, n. 2, p. 30-50, fev./abr. 1990.

CASTELLS, Manuel. La era de la información. Madrid: Alianza Editorial, 1997.

DAVIDOFF, Paul. Advocacy and pluralism in planning. Journal of the American Institute of Planners, v. 31, n. 4, p. 331-338, 1965.

ELMORE, Richard F. Backward mapping: implementation research and policy decisions. Political Science Quartely, v. 94, n. 4, p. 601-616, 1979,

GOGGIN, Malcolm L. et al. Implementation theory and practice: towards a third generation. Glenview: Scott, Foresman and Co., 1990.

GRINDLE, Merilee S. (Ed.). Politics and policy implementation in the Third World. Princeton: Princeton University Press, 1980.

(Ed.). Getting good government: capacity building in the public sectors of developing countries. Cambridge: Harvard Institute of International Development, 1988.

HEALEY, P. Collaborative planning: shaping places in fragmented societies. London: Macmillan, 1997.

HIBBARD, Michael; LURIE, Susan. Saving land but losing ground: challenges to community planning in the era of participation. Journal of Planning Education and Research, v. 20, n. 2, p. 187-195, 2000.

HOWARD, Ebenezer. Garden cities of tomorrow. London: Faber and Faber, 1902. 
IANNI, Otávio. Estado e planejamento econômico no Brasil. 3. ed. Rio de Janeiro: Civilização Brasileira, 1979.

KAUFAMN, Hebert. Administrative feedback. Washington, DC: The Brookings Institution, 1973.

LAFER, Bety N. Planejamento no Brasil. São Paulo: Perspectiva, 1970.

LINDBLOM, Charles E. The science of 'mudling through'. Public Administration Review, v. 19, p. 79-88, 1959.

LIPSKY, Michael. Street-level bureaucracy. New York: Russell Sage Foundation, 1980.

LOPES, Carlos Thomaz G. Planejamento, Estado e crescimento. São Paulo: Livraria Pioneira, 1990.

LUTZENBERGER, Jose. The World Bank’s Polonoroeste Project; a social and environmental catastrophe. The Ecologist, n. 1-2, p. 69-72, 1985.

MANOR, J. The political economy of democratic decentralization. Washington: The World Bank, 1999.

MATUS, Carlos. Política, planejamento e governo. Brasília: Ipea, 1993. Tomos I e II.

MAZMANIAN, Daniel A.; SABATIER, Paul A. Implementation and public policy. Chicago: Scott Foresman, 1983.

MIGDAL, Joel. Strong societies and weak States: State-society relations and State capabilities in the Third World. Princeton: Princeton University Press, 1988.

MORAN, Emilio F. (Org.). The dilemma of Amazonian development. Boulder: Westview Press, 1983.

NAJAM, Adil. Learning from the literature on policy implementation: a synthetic perspective. Luxenburg, Austria: IIASA, 1995. IIASA Working Paper 95-61.

OLIVEIRA, José A. Puppin de. Implementing environmental policies in developing countries through decentralization: the case of protected areas in Bahia, Brazil. World Development, v. 30, n. 10, p. 1713-1736, 2002.

- Enforcing protected area guidelines in Brazil: what explains participation in the implementation process? Journal of Planning Education and Research, 2005.

PALUMBO, Dennis J.; HARDER, Marvin A. Introduction. In: PALUMBO, Dennis J.; HARDER, Marvin A. (Eds.). Implementing public policy. Lexington: Lexington Books, 1981.

PRESSMAN, Jeffrey L.; WILDAVSKY, Aaron. Implementation. Berkeley: University of California Press, 1973.

REIN, Martin; RABINOVITZ, Francine F. Implementation: a theoretical perspective. Cambridge, MA: Joint Center for Urban Studies of MIT and Harvard University, 1977. (Working Paper, 43). 
RONDINELLI, Dennis A. Government decentralization in comparative perspective: theory and practice in developing countries. International Review of Administrative Sciences, v. 47, n. 2, p. 133-145, 1981.

SABATIER, Paul A. Top-down and bottom-up approaches to implementation research: a critical analysis and a suggested synthesis. Journal of Public Policy, v. 6, n. 1, p. 21-48, 1986.

SUSSKIND, Lawrence; KRUIKSHANK, Jeffrey. Breaking the impasse. New York: Basic Books, 1987.

TENDLER, Judith. Good governments in the tropics. Baltimore: Johns Hopkins University Press, 1987.

VAN METER, Donald; VAN HORN, Carl E. The policy implementation process. Administration and Society, v. 6, n. 4, p. 445-488, 1975. 